\title{
CORRESPONDENGE
}

\section{Diagnosis and Management of Upper Gastrointestinal Bleeding}

by Dr. med. Dr. phil. Erwin Biecker, Priv.-Doz. Dr. med. Jörg Heller, Priv.-Doz. Dr. med. Volker Schmitz, Prof. Dr. med. Frank Lammert, Prof. Dr. med. Tilman Sauerbruch in volume 5/2008

\section{Emergency Endoscopy}

We would like to point out the following problem. In the key word columns on page 86 , a reader in a rush will read "Every patient with a severe intestinal hemorrhage, [...] should first be hemodynamically stabilized in an intensive care or step-down unit."

This may lead to the conclusion that emergency endoscopy should not be initiated in parallel. However, this is a life saving measure in patients with arterial bleeds, e.g., Forrest Ia or esophageal varices.

DOl: 10.3238/arztebl.2008.346a

Dr. med. Joseph Pongratz

Dr. med. Shafiq Sadiq

Prof. Dr. med. Gerhard Pott

Dr. med. Winfried Winter

EUREGIO-Klinik

Hannoverstr. 5, 48529 Nordhorn, Germany
In Reply:

Our colleagues from Hanover make an important point and we are grateful to them for making it. Of course endoscopy should be initiated as speedily as possible, in parallel to hemodynamic stabilization and primary care, in patients with severe intestinal hemorrhage. As a rule, however, circulatory stabilization - if required on the intensive care ward - is usually feasible before endoscopy. In case of doubt (especially in a patient with an esophageal variceal bleed), intubation should be performed generously. Endoscopy that is too rapidly done in an instable patient can be life threatening for the patient, especially where monitoring options are insufficient. We therefore recommend assessing the individual patient's situation and treating what requires treatment before starting endoscopy.

DOI: 10.3238/arztebl.2008.346b

Prof. Dr. med. Tilman Sauerbruch

Direktor der Medizinischen Klinik und Poliklinik I

Universitätsklinikum Bonn

Sigmund-Freud-Str. 25, 53105 Bonn, Germany

Conflict of interest statement

The authors of all articles declare that they have no conflict of interest as defined by the guidelines of the International Committe of Medical Editors. 